\title{
DISTORTIONAL BUCKLING RESISTANCE OF THIN-WALLED PROFILES MADE OF STAINLESS STEEL
}

\author{
Jůza J.*, Jandera M.**
}

\begin{abstract}
The described research is focused on load-bearing capacity of compressed, stainless steel, thinwalled elements with a stiffener. This is typically a matter of trapezoidal sheeting design. An extensive numerical study was carried out with validation done on experiments from literature. As a result, a proposal of a distortional buckling curve specifically intended for stainless steel was made.
\end{abstract}

Keywords: Distortional buckling, Stainless steel, Buckling curve, Thin-walled sheet, Stiffener.

\section{Introduction}

The stress-strain behavior of stainless steel is very different from that of carbon steel. Whereas carbon steel has linear elastic behavior up to the yielding point, stainless steel has more non-linear behavior with no clearly visible yielding point. This phenomenon led to the formation of supplementary design rules for stainless steel structures. In Europe there is the design code EN 1993-1-4 (2006), which gives modifications to the carbon steel rules, in case stainless steel behavior differs significantly.

However, for the distortional buckling resistance (flexural buckling of a stiffener), there is no additional rule suggested for cold-formed, stainless steel sections in EN 1993-1-4 (2006), therefore the rule for carbon steel applies (1) - according to EN 1993-1-3 (2006):

$$
\begin{aligned}
& \chi_{\mathrm{d}}=1.0 \text { for } \bar{\lambda}_{\mathrm{d}} \leq 0.65 \\
& \chi_{\mathrm{d}}=1.47-0.723 \bar{\lambda}_{\mathrm{d}} \text { for } 0.65<\bar{\lambda}_{\mathrm{d}}<1.38 \\
& \chi_{\mathrm{d}}=\frac{0.66}{\bar{\lambda}_{\mathrm{d}}} \text { for } 1.38 \leq \bar{\lambda}_{\mathrm{d}}
\end{aligned}
$$

where the reduction factor $\chi_{\mathrm{d}}$ for the distortional buckling resistance is obtained from the non-dimensional slenderness $\overline{\lambda_{\mathrm{d}}}$.

The Eurocode for design of aluminium structures, EN 1999-1-4 (2007), contains a different formula for the distortional buckling (2). This reduction factor is significantly lower than the one for carbon steel over the whole slenderness range.

$$
\begin{aligned}
& \chi_{\mathrm{d}}=1.0 \text { for } \bar{\lambda}_{\mathrm{d}} \leq 0.25 \\
& \chi_{\mathrm{d}}=1.115-0.62 \bar{\lambda}_{\mathrm{d}} \text { for } 0.25<\bar{\lambda}_{\mathrm{d}}<1.04 \\
& \chi_{\mathrm{d}}=\frac{0.53}{\bar{\lambda}_{\mathrm{d}}} \text { for } 1.04 \leq \bar{\lambda}_{\mathrm{d}}
\end{aligned}
$$

As aluminium alloys exhibit a similar degree of non-linearity as stainless steels, it may indicate a lower reduction factor $\chi_{\mathrm{d}}$ applies to stainless steels as well.

There was only little investigation done so far at the Karlsruhe Institute of Technology (KIT) by Blaß and Ummenhofer (2010), with a distortional buckling curve proposal published later in Misiek et al. (2010). As expected, a significantly lower distortional buckling curve for stainless steel stiffeners was suggested.

\footnotetext{
* Ing. Jan Jůza.: Faculty of Civil Engineering, CTU in Prague, Thákurova 7; 166 29, Prague; CZ, jan.juza@fsv.cvut.cz

** Assoc. Prof. Michal Jandera, PhD.: Faculty of Civil Engineering, CTU in Prague, Thákurova 7; 166 29, Prague; CZ, michal.jandera@fsv.cvut.cz
} 


\section{Numerical model}

The numerical model of a thin-walled sheet with an intermediate stiffener was created in Abaqus/CAE 6.14-1. The experiments carried out by Blaß and Ummenhofer (2010) were numerically simulated at first.

The finite element model was made using four-node shell elements S4R. The boundary conditions were implemented to the model so that the model corresponds with the conditions of the above-mentioned research. Boundary conditions are shown in Fig. 1a. The numerical model was loaded by a uniaxial displacement of the top edge, so that it was compressed (Fig. 1b). Resulting load-bearing capacity of the model was determined as a maximum summation of the reactions of the top edge nodes during the process of loading.
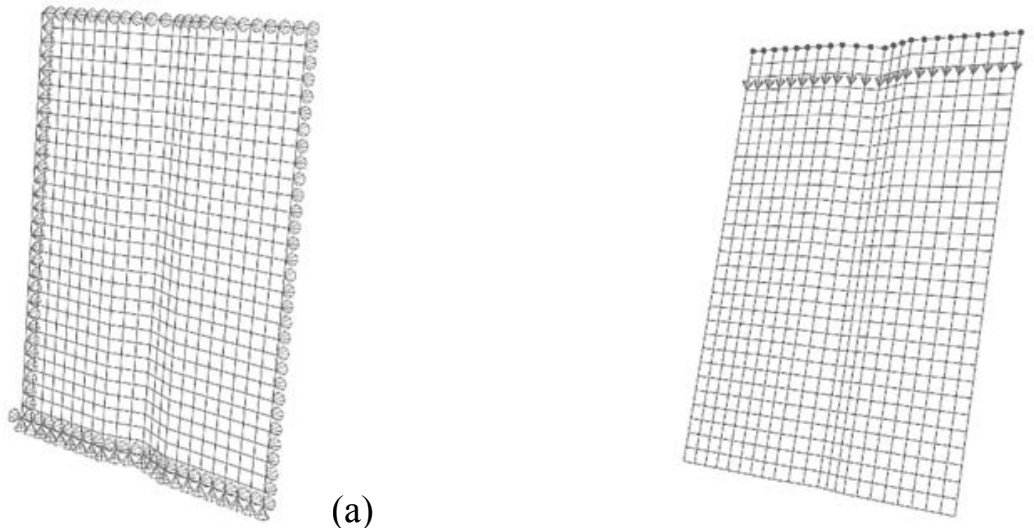

(a)

(b)

Fig. 1: Numerical model (a) boundary conditions, (b) loading by displacement.

Considering the material behavior of stainless steel, the stress-strain diagram curve is not possible to be accurately simplified by a bilinear function, as it is usual for carbon steels. For taking into account the material nonlinearity a two-stage Ramberg-Osgood model was used. It is given by formula (3) - this represents a modified expression, originally proposed by Mirambell and Real (2000).

$$
\varepsilon=\left\{\begin{array}{c}
\frac{\sigma}{E}+0.002\left(\frac{\sigma}{f_{\mathrm{y}}}\right)^{n} \text { for } \sigma \leq f_{\mathrm{y}} \\
\frac{\sigma-f_{\mathrm{y}}}{E_{\mathrm{y}}}+\left(\varepsilon_{u}-\frac{f_{\mathrm{u}}-f_{\mathrm{y}}}{E_{\mathrm{y}}}-\varepsilon_{0.2}\right)\left(\frac{\sigma-f_{\mathrm{y}}}{f_{\mathrm{u}}-f_{\mathrm{y}}}\right)^{n}+\varepsilon_{0.2} \text { for } f_{\mathrm{y}}<\sigma \leq f_{\mathrm{u}}
\end{array}\right.
$$

where the meaning of the model parameters and their most recent recommendation can be found in Arrayago et al. (2015). Experimentally measured values of steel grade 1.4301 (Blaß and Ummenhofer, 2010) were used for the stress-strain diagram in the numerical simulations of the mentioned experiments.

Geometric imperfections were implemented to the model. The imperfection magnitude and shape measurement were not investigated experimentally. These were considered by the shape of the elastic buckling eigenmodes. The eigenmodes were determined by a linear buckling analysis, method Lanczos, also in Abaqus software. According to EN 1993-1-5, the imperfection amplitude can be taken as $80 \%$ of the fabrication tolerances given in EN 1090-2 for the governing imperfection (not necessary the lowest buckling eigenmode but the one with higher influence on the resistance). Additional imperfections are further reduced to $70 \%$. Two elastic buckling eigenmodes were taken into account for imperfections of the model of the stiffened flange. One eigenmode for the distortional buckling and one eigenmode for the local buckling of the flat parts of the sheet. Elastic buckling eigenmodes for the local resp. distortional buckling are shown in Fig. 2.

The numerical model results were compared to the experimental ones. For all of the 48 specimens that had been previously tested experimentally at KIT, the average prediction was $12.9 \%$ lower (safe side) with quite significant standard deviation $(15.5 \%)$. The higher deviation in the results is contributed to the unknown values of imperfections of the tested specimens. 

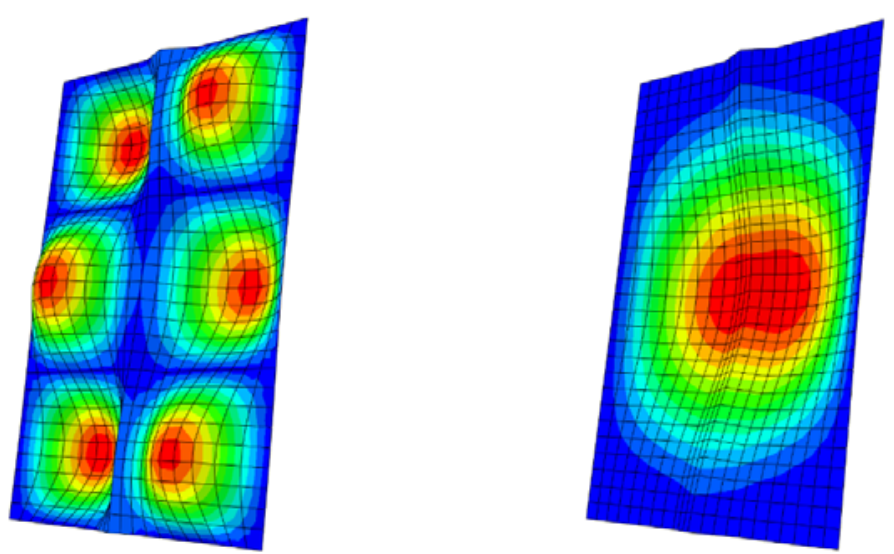

Fig. 2: Elastic buckling eigenmodes for the local (left) resp. distortional buckling (right).

\section{Parametric study}

Numerical models of thin-walled sheets with an intermediate stiffener were created for the parametric study. The models differed from each other in the geometry of the cross section and in the sheet thickness. The length of the model was always equal to ten times its width. The models were divided in two groups according to the geometry of the stiffener, to flanges with a narrow groove and flanges with a wide groove. In total, there were 60 different models according to the geometry. All of them were created in four different material variants. Two variants were made of austenitic steel, one variant was made of ferritic steel, and one variant was made of duplex steel. One austenitic variant represents the average values from the experimental tests. The other three variants represent the values for cold-rolled stainless steel sections as recommended by Afshan et al. (2019).

All the models were loaded by displacement and their load-bearing capacities were numerically determined. Afterwards, elastic critical stress and relative slenderness were analytically calculated for every model, using the reduction factor for local buckling from EN 1993-1-4/A1, according to Gardner and Theofanous (2008). Since the load-bearing capacity had been already known from the numerical simulation, the reduction factor $\chi_{\mathrm{d}}$ for the distortional buckling resistance could have been iteratively calculated. The resulting values of the non-dimensional slenderness for the distortional buckling and the reduction factor $\chi_{\mathrm{d}}$ for particular models were plotted to the chart so as to be assessed (Fig. 3). The comparison is done with the codified distortional buckling curves for carbon steel and for aluminium, and with the buckling curve proposed by Misiek et al. (2010). There are three separate charts, each one for a different material type.

It is clear from the comparison of the above mentioned buckling curves, that the resulting points from the parametric study are corresponding the best to the curve proposed by Misiek et al. (2010). However, there is a considerable deviation of the results for lower slendernesses of the stiffener. Concerning the codified distortional buckling curves, the buckling curve for aluminium (EN 1999-1-4) is closer to the results for stainless steel. The buckling curve for carbon steel (EN 1993-1-3) appears to be the least suitable. Almost all the results are under the curve, which means that the curve is significantly unsafe for stainless steel.

\section{Proposal of a distortional buckling curve for stainless steel}

The proposal of the distortional buckling curve for stainless steel was the main output of the parametric study. The proposal is given by formula (4):

$$
\begin{aligned}
& \chi_{\mathrm{d}}=1.0 \text { for } \bar{\lambda}_{\mathrm{d}} \leq 0.36 \\
& \chi_{\mathrm{d}}=1.324-0.9 \bar{\lambda}_{\mathrm{d}} \text { for } 0.36<\bar{\lambda}_{\mathrm{d}}<0.91 \\
& \chi_{\mathrm{d}}=\frac{0.46}{\bar{\lambda}_{\mathrm{d}}} \text { for } 0.91 \leq \bar{\lambda}_{\mathrm{d}}
\end{aligned}
$$

The determination of the formula with its parameters was based on two criteria. The first criterion was the least-squares method, i.e., minimizing the sum of the squares of the errors that were generated by the results of the parametric study and the values according to the curve. The second criterion was the reliability 
analysis. The distortional buckling curve was designed so as to satisfy the codified value of the partial safety factor $\gamma_{\mathrm{M} 0}=1.1$.
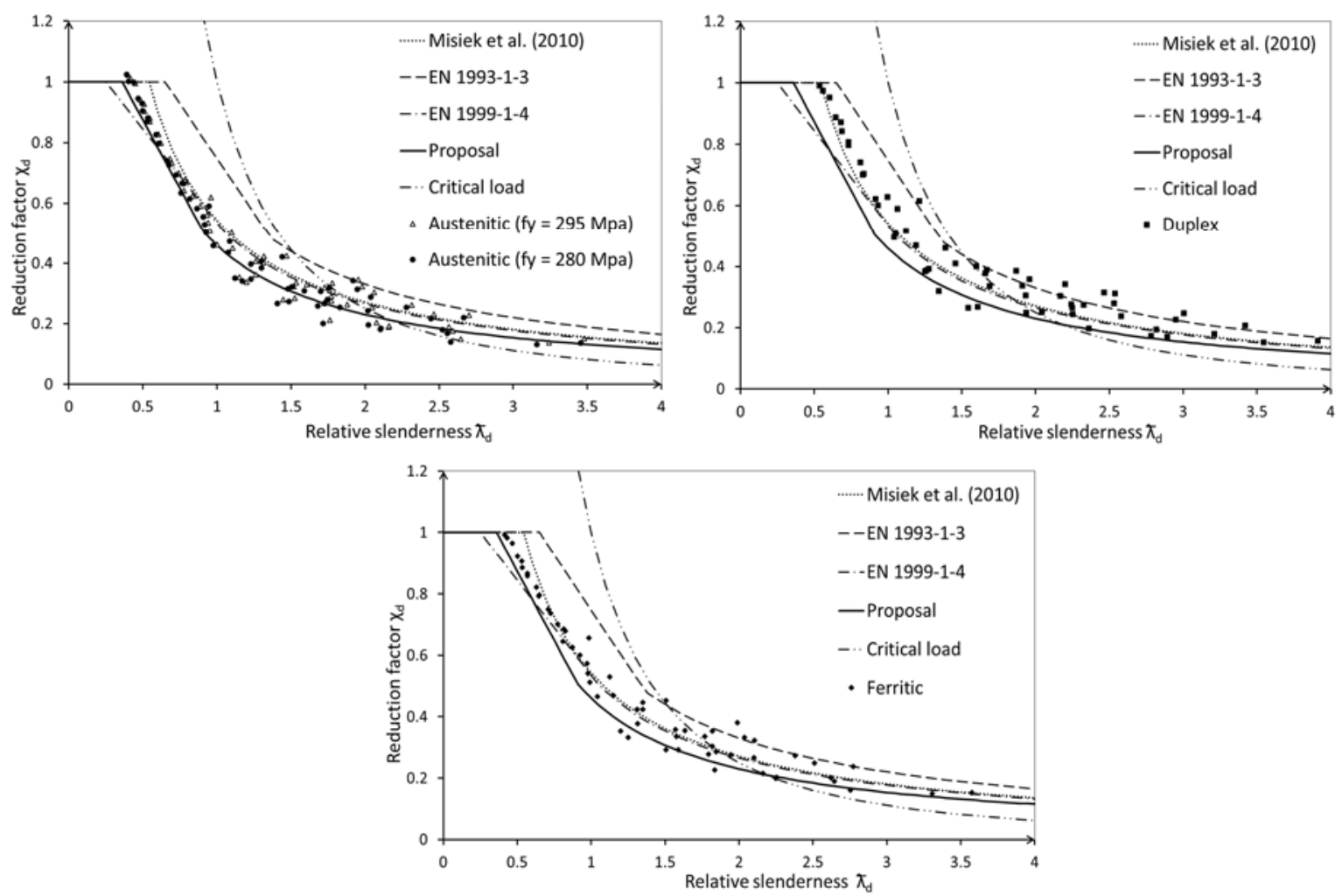

Fig. 3: Distortional buckling $\chi_{d}$ for austenitic, duplex and ferritic steel.

\section{Acknowledgement}

The authors would like to thank to Thomas Misiek for his support and consultations. The support of the Czech Science Foundation project: Global analysis methods for slender structures of stainless steels and other steels with nonlinear stress-strain diagram (20-24563S) is gratefully acknowledged.

\section{References}

Afshan, S., Zhao, O. and Gardner, L. (2019) Standardised material properties for numerical parametric studies of stainless steel structures and buckling curves for tubular columns. Journal of Constructional Steel Research 152: 2-11.

Arrayago, I., Real, E. and Gardner, L. (2015). Description of stress-strain curves for stainless steel alloys. Materials and Design 87: 540-552.

Blaß, H. J. and Ummenhofer, T. (2010) Stahltrapezprofile aus nichtrostenden Stählen. Bericht Nr.: 091503 Karlsruher Institut für Technologie (KIT).

EN 1090-2 (2008) Execution of steel structures and aluminium structures - Part 2: Technical requirements for steel structures. Brussels: European Committee for Standardization (CEN).

EN 1993-1-3 (2006) Eurocode 3 - Design of steel structures, Part 1-3: General rules - Supplementary rules for coldformed members and sheeting. Brussels: European Committee for Standardization (CEN).

EN 1993-1-4 (2006) Eurocode 3 - Design of steel structures, Part 1-4: General rules - Supplementary rules for stainless steels. Brussels: European Committee for Standardization (CEN).

EN 1993-1-5 (2006) Eurocode 3 - Design of steel structures, Part 1-5: Plated structural elements. Brussels: European Committee for Standardization (CEN).

EN 1999-1-4 (2007) Eurocode 9 - Design of aluminium structures, Part 1-4: Cold-formed structural sheeting. Brussels: European Committee for Standardization (CEN).

Gardner, L. and Theofanous, M. (2008) Discrete and continuous treatment of local buckling in stainless steel elements. Journal of Constructional Steel Research 64(11), 1207-1216.

Mirambell, E. and Real, E. (2000) On the calculation of deflections in structural stainless steel beams: an experimental and numerical investigation. Journal of Constructional Steel Research 54 (4): 109-133.

Misiek, T., Krüger, H., Kathage, K. and Ummenhofer, T. (2010) Buckling of stiffeners for stainless steel trapezoidal sheeting. Steel Construction 3(4): 225-230. 